\title{
Thermofluidynamic Analysis of a Combustor Chamber Coupled to a Biomass Downdraft Gasifier
}

\author{
Jofran Luiz de Oliveira, ${ }^{1}$ Márcio Arêdes Martins, ${ }^{2}$ Jadir Nogueira da Silva, ${ }^{2}$ \\ Michel de Oliveira dos Santos, ${ }^{2}$ and William Rosário dos Santos ${ }^{2}$ \\ ${ }^{1}$ Institute of Agricultural and Technological Science-Agricultural and Environmental Engineering, \\ Federal University of Mato Grosso (UFMT), 78735-901 Rondonópolis, MT, Brazil \\ ${ }^{2}$ Department of Agricultural Engineering, Federal University of Viçosa (UFV), 36570-000 Viçosa, MG, Brazil
}

Correspondence should be addressed to Jofran Luiz de Oliveira, jofran@ufmt.br

Received 18 April 2012; Accepted 13 August 2012

Academic Editors: M. Beccali, A. Bosio, H. K. Ozturk, and A. C. Rastogi

Copyright (C) 2012 Jofran Luiz de Oliveira et al. This is an open access article distributed under the Creative Commons Attribution License, which permits unrestricted use, distribution, and reproduction in any medium, provided the original work is properly cited.

Biomass is one of the most promising renewable energy sources. Abundantly, the potential as an alternative source to meet the world energy demand has been widely acknowledged. Gasification is one of the most efficient processes concerning thermochemical conversion, having as objective the production of a gas with useful energy power, known as producer gas. In order to optimize thermochemical processes such as the combustion of gases and subsequent gas mixture, computer modeling is becoming an important tool. Aiming to improve the performance of a combustion chamber, previously coupled to a downdraft gasifier, a thermofluidynamic model was elaborated and validated, using the concepts of computational fluid dynamics (CFD). It was reported that temperature, pressure, and velocity distributions of the computational model showed good consistency with experimental data, which allows using this model to predict the performance of this type of combustion chambers.

\section{Introduction}

Currently, there is a world interest concerning the technological development for exploration of renewable energy sources, both for environmental and economic reasons. It is also understood that the importance of using biomass energy is mainly to provide clean energy with a null balance of $\mathrm{CO}_{2}$ in the greenhouse effect and in being an excellent fixation of carbon.

Gasification is a process of thermochemical conversion that uses heat to convert solid biomass, or other carbonaceous into a gaseous fuel also known as producer gas. Through gasification, it is possible to convert practically any solid biomass residue in a clean and renewable gas fuel, which can be used in internal combustion motors for generating mechanical or electrical energy, heating for environments, or drying of agricultural products [1].

Biomass gasification is an efficient and advanced technology used for energy extraction, and has been calling attention especially due to its potential usages [2]. Martin et al. [3] tested a downdraft biomass gasifier coupled to a gas combustor to produce heated air for drying of agricultural products. Berggren et al. [4] investigated the energy potential of biomass and coal gasification in the Polish system of power generation. Zanatta et al. [5], in poultry houses heating, used air heated by biomass gasification and producer gas combustion. Santos et al. [6] developed a system to control temperature of heated air in combustor chamber for producer gas, focusing heating in poultry houses.

Computational modeling has become an important tool for project and development of machines, equipments, and systems. Kiliç [7] (1996) presented a study of computational flow and heat convection in a reverse flow combustion chamber, and showed that in general heat transfer in these chambers can be maximized when chosen correctly the geometry of the combustor according to the qualitative properties of the exhaust gas. Khoshhal et al. [8] assessed a solution to prevent ruptures in boiler pipes, in overheated region by computational fluid mechanics (CFD), and showed that inlet air temperature has no meaningful cool significance, 
due to the high transfer rate of heat in pipes. Sreekanth et al. [9] developed a 2D model for establishing time of devolatilization in wood cylinders, in a bubbling fluidized bed combustor, whereas Gungor [10] proposed a model for simultaneous prediction of hydrodynamic, heat transference, and combustion aspects, in circulating and fluidized bed biomass combustors. Osório et al. [11] validated a 3D model to estimate the energy balance for a broiler house with misting cooling. Damasceno et al. [12] presented a review about the use of computational fluid dynamics in animal production facilities, and showed that the use of this tool to predict and analyze the efficiency of involved systems has been increased.

Aiming at improving the performance of a combustion chamber coupled to a downdraft gasifier, a 3D thermofluidynamics study was elaborated in computational fluid dynamics (CFD).

\section{Material and Methods}

The research was developed at BioCFD (Laboratory of Computational Fluid Mechanics Applied to Bioprocesses), Department of Agricultural Engineering of the Federal University of Viçosa. The software ANSYS CFX 11.0 was used for fluid flow simulation in a combustion chamber, which had its geometry generated from the project of a downdraft gasifier installed in the area of energy in agriculture, of the same department.

2.1. Characteristics of the Gasifier. The gasifier provides fuel that follows to the combustion chamber where it is burnt and next mixed to the air by primary and secondary air inlets, to provide gas at the interest temperature. (Figures $1(\mathrm{a})$ and 1(b)). The gasifier used in this experiment has a cocurrent flow set. It was developed to convert biomasses with high content of volatile compounds in a gas with low tar assay [3].

The combustion chamber was coated with refractory bricks, providing an external temperature near the room temperature, being considered adiabatic for simulation effects. The chamber was designed in two parts connected by a pipe. The first part "primary chamber" is where producer gas is combusted and hot air can be mixed to fresh air from primary and secondary inlets. The second part "secondary chamber" was designed to control air temperature in outlet, adding extra fresh air in the chamber. However, it was not used in this experiment.

2.2. Conditions of Operation and Experimental Procedures. To systematically follow, assess, and control the parameters that will determine the best performance status of the system the following variables were monitored: external air temperature, air temperature of combustor inlet and outlet, air flow of primary and secondary inlets, and air flow of combustor inlet and outlet.

To measure the temperature, K-type shielded thermocouples (Chromel + Alumel) were used, allowing for the temperature to be measured in the interval 0 to $1300^{\circ} \mathrm{C}$, with a sensitivity of $39.4 \mu \mathrm{V}^{\circ} \mathrm{C}^{-1}$. Measurements were performed during a period of four hours in five minutes intervals,

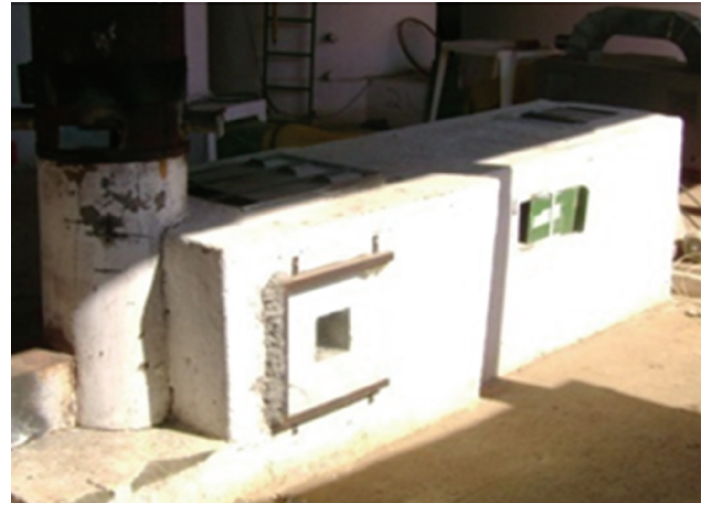

(a)

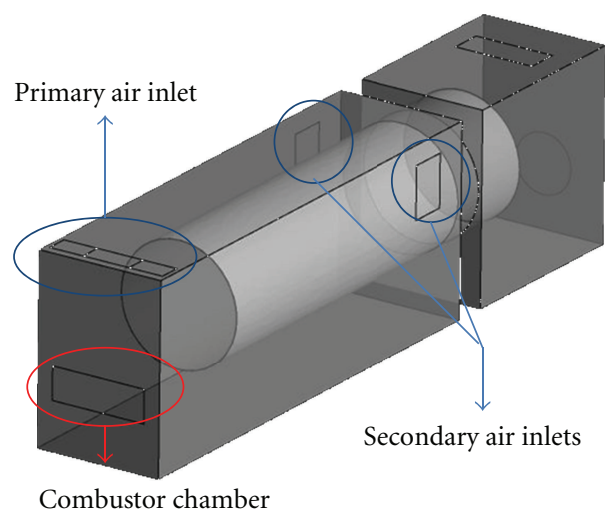

(b)

FIgURE 1: (a) Set gasifier/combustor and (b) geometry generated by simulation.

with three repetitions. For measuring room temperature a thermometer (brand ISUZU) was used.

Measurements of velocities were performed by hot-wire anemometers (brand Hygrotherm), where outlet air velocity was controlled through a motor coupled to a frequency inverter remaining approximately at $6.56 \mathrm{~m} \mathrm{~s}^{-1}$.

The results of the model obtained in CFD were checked and compared with the corresponding data experimentally obtained. For such, the consistency among measured and predicted values in the model in CFD was assessed by normalized square mean of error (NMSE). NMSE values inferior to 0.25 are considered good indicators of consistency [13]:

$$
\text { NMSE } \left.=\frac{\left(\overline{C_{p}-C_{o}}\right)^{2}}{\left(C_{p m} \cdot C_{o m}\right.}\right),
$$

where

$$
\left(\overline{C_{p}-C_{o}}\right)^{2}=\frac{\sum_{n}\left(C_{p i}-C_{o i}\right)^{2}}{n}
$$

2.3. Geometry and Mesh. The initial step consists in the definition of calculation domain, a geometry in which the mathematical model will be applied, which describe the phenomena to be investigated. The mesh was generated in the software ANSYS ICEM. 
TABLE 1: Contour conditions.

\begin{tabular}{lccc}
\hline Combustor inlet & $T_{1}=124.0^{\circ} \mathrm{C}$ & $T_{2}=101.0^{\circ} \mathrm{C}$ & $T_{3}=80.0^{\circ} \mathrm{C}$ \\
Primary air inlet & $T=19.3^{\circ} \mathrm{C}$ & $v=2.127 \mathrm{~m} \mathrm{~s}^{-1}$ & \\
Secondary air inlet & $T=19.3^{\circ} \mathrm{C}$ & $v=2.127 \mathrm{~m} \mathrm{~s}^{-1}$ & \\
Walls & Adiabatic & No sliding & $P=0 \mathrm{~Pa}$ \\
Outlet & $\partial T / \partial \vec{u}=0$ & $v=6.56 \mathrm{~m} \mathrm{~s}^{-1}$ & $P \mathrm{~m} \mathrm{~s}^{-1}$ \\
\hline
\end{tabular}

2.4. Governing Equations. The model that described the nonisothermal fluid flow in the combustion chamber of the gasifier is described by equations of continuity, momentum, and energy, simplified next [14]:

$$
\begin{gathered}
\nabla \cdot(\rho \mathbf{U})=0 \\
\nabla \cdot(\rho \mathbf{U U})=-\nabla p+\nabla \cdot\left[\mu_{t}\left(\nabla \mathbf{U}+\nabla \mathbf{U}^{T}\right)\right], \\
\nabla \cdot\left(-k \nabla T+\rho C_{p} T \mathbf{U}\right)=Q .
\end{gathered}
$$

The turbulent flow was modeled by $k-\varepsilon$ standard model [15], which assess viscosity $\mu_{t}$ from a ratio between turbulent kinetic energy $(k)$ and dissipation of turbulent kinetic energy $(\varepsilon)$.

$$
\mu_{t}=\rho C_{\mu} \frac{k^{2}}{\varepsilon}
$$

in which $k$ values and $\varepsilon$ are obtained by the following equations:

$$
\begin{aligned}
-\nabla \cdot\left[\left(\eta+\rho \frac{C_{\mu}}{\sigma_{k}} \frac{k^{2}}{\varepsilon}\right) \nabla k\right]+\rho U \cdot \nabla k \\
=\rho C_{\mu} \frac{k^{2}}{\varepsilon}\left(\nabla U+\nabla U^{T}\right)^{2}-\rho \varepsilon \\
-\nabla \cdot\left[\left(\eta+\rho \frac{C_{\mu}}{\sigma_{\varepsilon}} \frac{k^{2}}{\varepsilon}\right) \nabla \varepsilon\right]+\rho U \cdot \nabla \varepsilon \\
=\rho C_{\varepsilon 1} C_{\mu} k\left(\nabla U+\nabla U^{T}\right)^{2}-\rho C_{\varepsilon 2} \frac{\varepsilon^{2}}{k} .
\end{aligned}
$$

For experimental validation, the model was simulated from the actual conditions experimentally performed, assuming turbulence intensity of $5 \%$. Contour conditions for simulation of the combustor are shown in Table 1.

The conditions of permanent regimen and turbulent and incompressible flow were assumed. Computational domain, governing equations, considered physical models, boundary conditions, and solution methods are described in the following sections. For each experimental repetition it was taken one combustor inlet temperature $\left(T_{1}, T_{2}\right.$, and $\left.T_{3}\right)$. Inlets and outlet air velocity and room temperature were constant in repetitions. It was performed one computational simulation per repetition.

\section{Results and Discussion}

3.1. Generation of Mesh. The computational mesh was generated using the ANSYS ICEM CFD. The mesh chosen for the

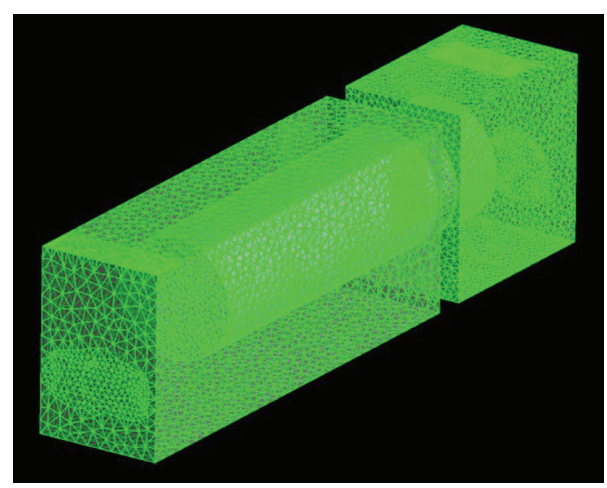

Figure 2: Topology adopted and computational mesh.

TABLe 2: Experimental and simulation temperature values.

\begin{tabular}{ccccccc}
\hline$T_{1}$ & $T_{2}$ & $T_{3}$ & Mean & Deviation & $\begin{array}{c}\text { Standard } \\
\text { error }\end{array}$ & NMSE \\
\hline T Exp. ${ }^{\circ} \mathrm{C} \mathbf{4 9 . 0 0}$ & $\mathbf{4 7 . 0 0}$ & $\mathbf{4 3 . 0 0}$ & 46.33 & 3.06 & $\mathbf{2 . 0 0}$ & $\mathbf{0 . 0 1 3 2}$ \\
T Sim. ${ }^{\circ} \mathrm{C} \mathbf{4 7 . 7 5}$ & $\mathbf{4 1 . 4 5}$ & $\mathbf{3 6 . 3 5}$ & 41.35 & 5.71 & & \\
\hline
\end{tabular}

considered control volume is the mix type with tetrahedral predominance. After several refinements, the selected mesh was generated, especially in the hot air inlet regions and in the mixture region, in a total of 38900 nodes, with 166024 mixed elements (Figure 2).

The mesh topology is used in order to monitor the development of opening air jet, focusing on refining the shear zone between currents of hot and cold air. Previous studies were conducted to verify if the size distribution of elements of the mesh is adequate. The computational mesh shown in Figure 2 already minimizes the error associated with spatial discretization.

3.2. Experimental Validation. Concerning the outlet temperature, simulation values were compared with experimental values (Table 2 ).

A comparison among data obtained by the proposed model developed in CFD and experimental measures of outlet air temperature of the combustor show that mean temperature values did not significantly differ between experimental values and model values, and they have a normalized mean square error (NMSE) of 0.0132 and correlation coefficient 0.9687 , which indicates a good consistency among results, thus concluding that the model can be used to predict the thermal and dynamic fluid behavior of the developed combustor. 


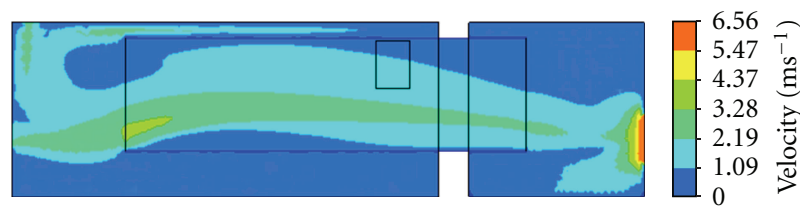

(a)

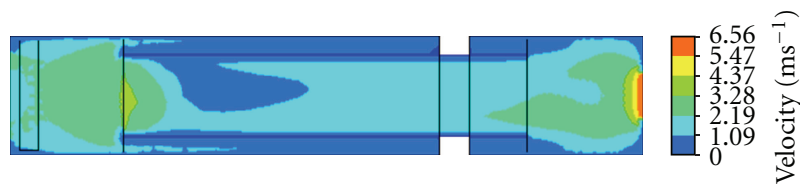

(b)

FIgURE 3: Velocity distribution. (a) Lateral symmetry plan and (b) central plan with upper view.

3.3. Model Validated. It is observed that the simulated flow has a deficient recirculation in the inlet duct (Figures 3(a) and $3(b)$ ). The regions of recirculation are beneficial for the separation of particulates from the gasification process, especially when the gasifiers have cocurrent flow. The Reynolds number found for the combustor was 68,797 , indicating a system with turbulent behavior.

The velocity distribution shows regions of low velocities within the combustor, especially at the bottom of the pipe within the primary chamber. These regions have almost zero velocity and no apparent function, only increasing the project cost, an aspect that can be improved in future projects.

Streamlines (Figure 4(a)) generated from the combustor inlet and primary and secondary air inlets detail the flow of the fluid, according to the vector position and flow. It is observed in this case the lack of mixing in the duct, which can be understood as a system deficiency.

The velocity vectors (Figure 4(b)) allow distinguishing the fluid direction depending on the position, thus permitting a detailed analysis of the study area. It can be observed in the duct region between the two chambers, a discrete region of recirculation in the upper portion of the initial and end of the pipe, which can be influenced by the dissipation of kinetic energy at the duct inlet.

The secondary chamber of the combustor, in which the channeling of mixed air occurs, is the place where we observe a higher pressure gradient, as seen in Figure 5(a). A variation of mean pressure of 25.96 $\mathrm{Pa}$ was calculated, and this pressure drop was considered negligible.

As expected, the primary chamber has the highest thermal gradient of the combustor. There is clearly a mixing region near the inlet pipe and a region of low speed around the pipe in the primary chamber of the combustor (Figure 5(b)). Pipe and secondary chamber do not show their homogenization function, being clearly noticeable the divergence between cold and hot air layers. In spite of these problems, the setting selected for the simulated combustor established an air resulting from thermal energy useful for drying grains, with a mean temperature of $41.35^{\circ} \mathrm{C}$, consistent with the experimental value.

\section{Conclusions}

In this work, a 3D model was developed and implemented for a producer gas combustor from a biomass gasifier. Simulated values were compared to experimental values, which showed a good correlation.

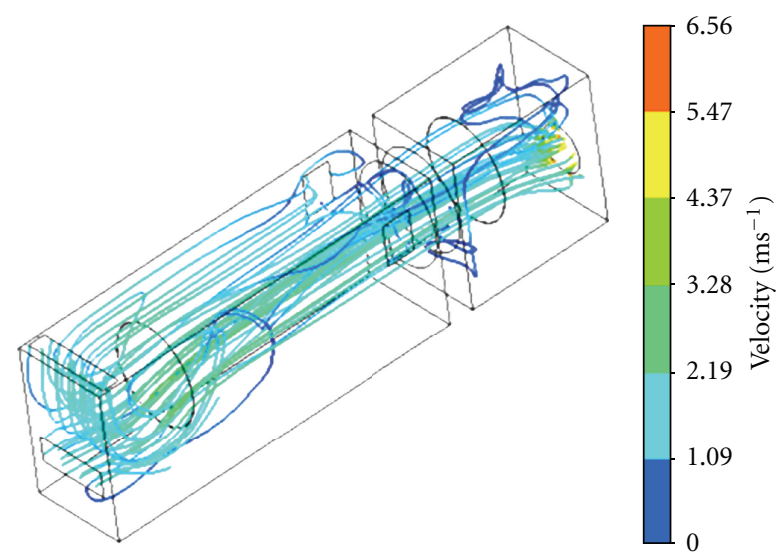

(a)

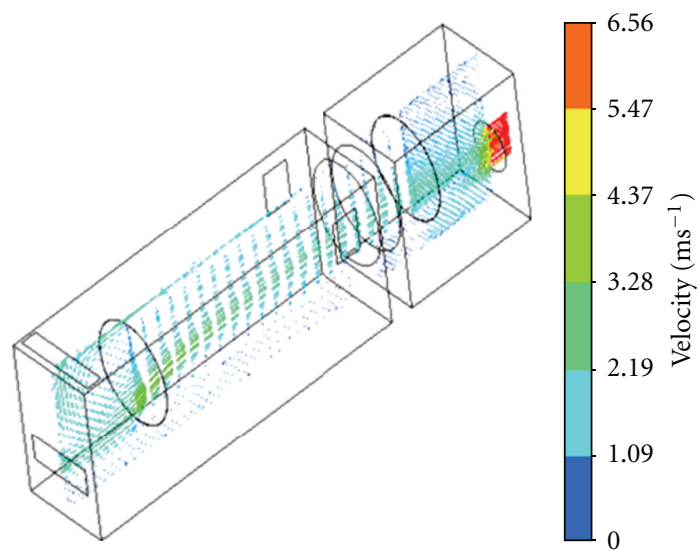

(b)

FIGURE 4: (a) Streamlines and (b) velocity vectors in the combustor.

The numerical analysis allowed a view of the phenomena associated with the heat transfer and fluid flow, which would not be possible by means of experimental procedures. The model results from this study ensured detailed information about the behavior of fluid in the combustor, based on an inside look of scalar fields of velocity, temperature, and pressure, resulting in a better understanding of the studied phenomena. Performed simulations suggest the structural change in primary and secondary chambers as the removal of "dead" zones, thus making a better process efficiency possible.

Further studies should include structural changes such as variation of hot and cold air inlet areas, removal of pipeline 


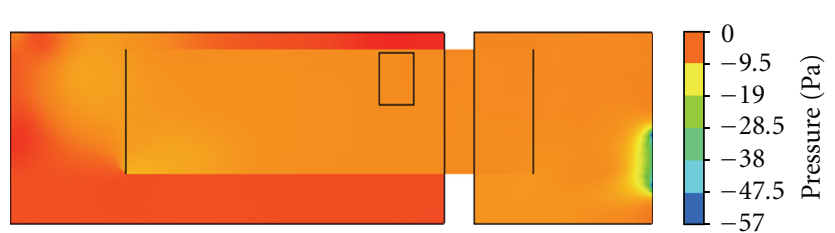

(a)

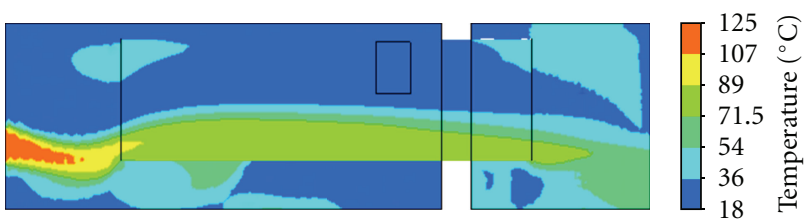

(b)

Figure 5: (a) Pressure distribution and (b) temperature distribution in the combustor.

in the first chamber, and different geometric configurations of primary and secondary chambers.

\section{Nomenclature}

$C_{p}:$ Specific heat, $\mathrm{J} / \mathrm{KgK}$

$k: \quad$ Thermal conductivity $\mathrm{W}(\mathrm{m} \cdot \mathrm{k})^{-1}$

$P$ : $\quad$ Pressure, $\mathrm{N} / \mathrm{m}^{2}$

Q: $\quad$ Thermal source, $\mathrm{W} \mathrm{m}^{-3}$

T: $\quad$ Temperature, $\mathrm{K}$

$U$ : Velocity vector

$C_{p i}$ : Predicted value

$C_{o i}:$ Measured value

$C_{p m}$ : Mean predicted value

$C_{o m}$ : Mean measured value

$n$ : Number of measurements.

\section{Greek Symbols}

$\rho:$ Density, $\mathrm{Kg} / \mathrm{m}^{3}$

$\mu$ : Dynamic fluid viscosity, $\mathrm{Kg} / \mathrm{ms}$

$\kappa$ : Turbulent kinetic energy, $\mathrm{m}^{2} \mathrm{~s}^{-2}$

$\varepsilon$ : Dissiation of turbulent kinetic energy, $\mathrm{m}^{2} \mathrm{~s}^{-3}$

$\eta$ : Mean flow and time scale ratio.

\section{Subscript}

$t$ : Turbulent.

\section{Superscript}

$T$ : Transpose of tensor.

\section{Constants}

$C_{\mu}: 0.09$

$C_{\varepsilon 1}: 1.44$

$C_{\varepsilon 2}: 1.92$

$\sigma_{\varepsilon}: 1.3$

$\sigma_{\kappa}: 1.0$.

\section{Acknowledgments}

The authors would like to thank the Brazilian Government Agency FAPEMIG and the National Council of Technological and Scientific Development CNPq for their financial support.

\section{References}

[1] M. Baratieri, P. Baggio, L. Fiori, and M. Grigiante, "Biomass as an energy source: thermodynamic constraints on the performance of the conversion process," Bioresource Technology, vol. 99, no. 15, pp. 7063-7073, 2008.

[2] D. Y. C. Leung, X. L. Yin, and C. Z. Wu, "A review on the development and commercialization of biomass gasification technologies in China," Renewable and Sustainable Energy Reviews, vol. 8, no. 6, pp. 565-580, 2004.

[3] S. Martin, J. N. Silva, I. F. F. Tinoco, A. C. Vieira, and F. L. Zannata, "Design and construction of a downdraft gasifier for biomass," Engenharia na Agriculturav, vol. 14, pp. 238-249, 2006 (Portuguese).

[4] M. Berggren, E. Ljunggren, and F. Johnsson, "Biomass cofiring potentials for electricity generation in Poland-Matching supply and co-firing opportunities," Biomass and Bioenergy, vol. 32, no. 9, pp. 865-879, 2008.

[5] F. L. Zanatta, J. N. Silva, I. F. F. Tinoco, D. Oliveira Filho, and S. Martin, "Evaluation of thermal comfort in poultry house heated by a biomass gasifier," Engenharia na Agricultura, vol. 16, pp. 270-284, 2008 (Portuguese).

[6] W. R. Santos, J. N. Silva, D. Oliveira Filho, and M. A. Martins, "Control and evaluation of a set gasifier-combustor with cocurrent flow using eucalyptus wood as a fuel," Engenharia na Agricultura, vol. 18, pp. 165-170, 2010 (Portuguese).

[7] M. Kiliç, "Flow and convective heat transfer in cylindrical reversed flow combustion chambers," International Communications in Heat and Mass Transfer, vol. 23, no. 8, pp. 11511161, 1996.

[8] A. Khoshhal, M. Rahimi, and A. A. Alsairafi, "CFD investigation on the effect of air temperature on air blowing cooling system for preventing tube rupture," International Communications in Heat and Mass Transfer, vol. 36, no. 7, pp. 750-756, 2009.

[9] M. Sreekanth, D. R. Sudhakar, B. V. S. S. S. Prasad, A. K. Kolar, and B. Leckner, "Modelling and experimental investigation of devolatilizing wood in a fluidized bed combustor," Fuel, vol. 87, no. 12, pp. 2698-2712, 2008.

[10] A. Gungor, "Two-dimensional biomass combustion modeling of CFB," Fuel, vol. 87, no. 8-9, pp. 1453-1468, 2008.

[11] S. J. A. Osório, I. F. F. Tinoco, and M. O. Paula, "Modeling and experimental validation to estimate the energy balance for a broiler house with misting cooling," Dyna, vol. 79, p. 10, 2011.

[12] F. A. Damasceno, F. C. Baeta, M. A. Martins, S. J. A. Osório, and S. J. A. I. Tinoco, "Computational fluid dynamics (CFD) and it's use for analysis gas distribution inside animal production facilities: a literature review," Revista U.D.C.A Actualidad \& Divulgación Científica, vol. 14, pp. 23-34, 2011.

[13] M. P. Anderson and W. W. Woessner, Applied Groundwater Modeling: Simulation of Flow and Advective Transport, Academic Press, 2nd edition, 1992.

[14] A. H. A. Motlagh and S. H. Hashemabadi, "3D CFD simulation and experimental validation of particle-to-fluid heat 
transfer in a randomly packed bed of cylindrical particles," International Communications in Heat and Mass Transfer, vol. 35, no. 9, pp. 1183-1189, 2008.

[15] B. E. Launder and D. B. Spalding, "The numerical computation of turbulent flows," Computer Methods in Applied Mechanics and Engineering, vol. 3, no. 2, pp. 269-289, 1974. 

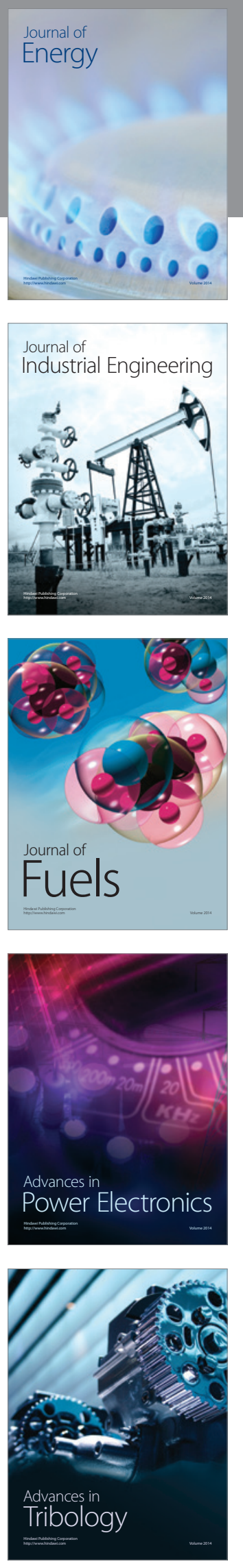
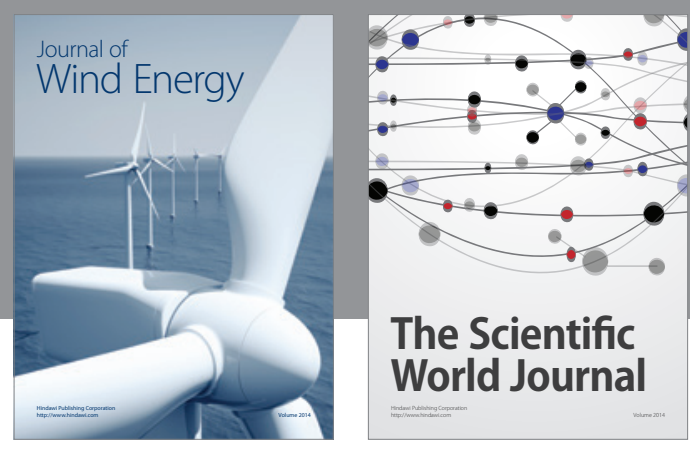

The Scientific World Journal

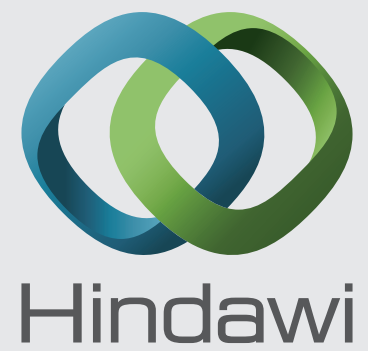

Submit your manuscripts at http://www.hindawi.com
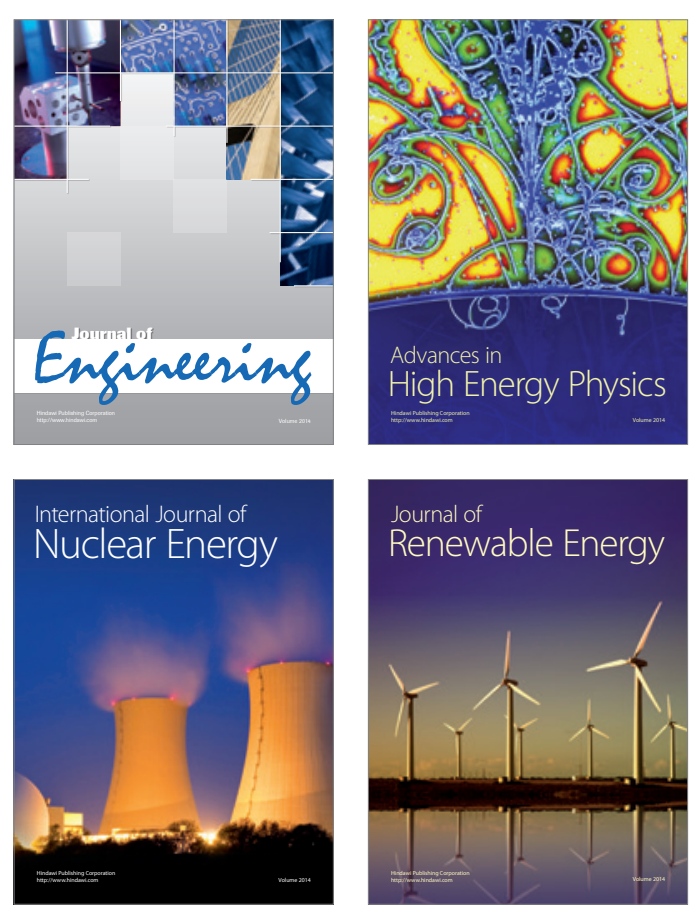

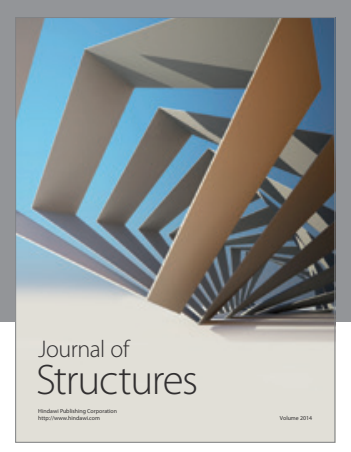

Rotating
Mechinery
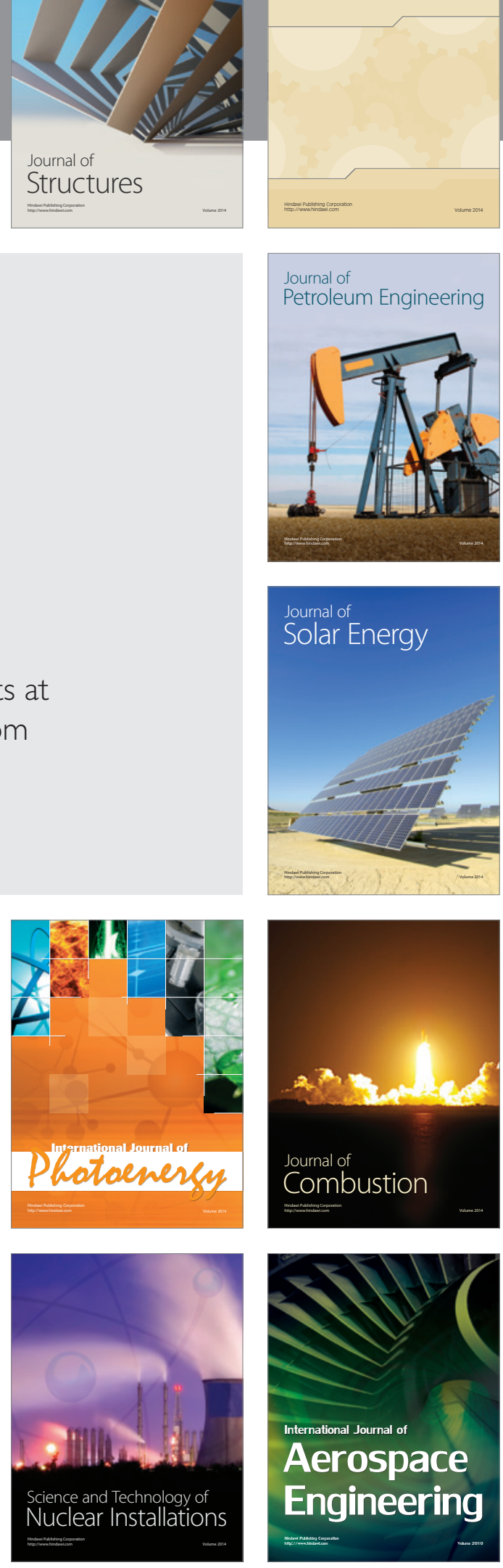